\title{
SEGUNDA RESTAURACIÓN DE BURSERA OVALIFOLIA Y NOMBRE NUEVO PARA OTRO COMPONENTE DEL COMPLEJO DE B. SIMARUBA (BURSERACEAE)*
}

\author{
Jerzy Rzedowski¹, Rosalinda Medina Lemos² y Graciela Calderón de Rzedowski ${ }^{1}$ \\ ${ }^{1}$ Instituto de Ecología, A.C., Centro Regional del Bajío, \\ Apdo. postal 386, 61600 Pátzcuaro, Michoacán, México. \\ ${ }^{2}$ Universidad Nacional Autónoma de México, Instituto de Biología, \\ Apdo. postal 70-233, 04510 México, D.F., México.
}

\section{RESUMEN}

Uno de los grupos taxonómicamente más difíciles del género Bursera es el que comprende los elementos ubicados alrededor de B. simaruba, pues varias de tales especies son morfológicamente tan parecidas que no siempre resultan fáciles de distinguir de esta última entidad, a la vez muy variable, ni tampoco muchas veces entre sí.

En 1936 Bullock redujo a varios componentes de este conjunto a la sinonimia de uno solo, para el que usó el nombre de B. ovalifolia (Schltdl.) Engl., pues juzgó que la propia B. simaruba, cuyo tipo procede de Jamaica, no existe en México. Estudios posteriores, sin embargo, indicaron que muchas poblaciones de nuestro país son suficientemente semejantes a las plantas antillanas para considerarlas pertenecientes a este último taxon y en consecuencia el epíteto de Schlechtendal cayó en desuso.

En esta contribución se reivindica la denominación B. ovalifolia para una especie caracterizada por frutos relativamente pequeños y hojas con 3 o 5 (rara vez 7) foliolos abruptamente acuminados o cuspidados en el ápice, glabros o con escasa pubescencia desde su juventud. Tales plantas se distribuyen desde la comarca costera de Jalisco al menos hasta Costa Rica y son particularmente abundantes en la región oaxaqueña del Istmo de Tehuantepec, donde registran una gran diversidad de formas de foliolos.

Por otra parte se propone el nombre de B. roseana para otro miembro de este conjunto, originalmente descrito como Terebinthus acuminata y que hasta ahora no se había transferido de forma legítima al género Bursera. Este taxon, que prospera esencialmente en altitudes superiores a $1200 \mathrm{~m}$, no pocas veces en convivencia con encinares y pinares, extiende su área de distribución desde Nayarit, Zacatecas y Aguascalientes hasta el Estado de México y Guerrero.

\footnotetext{
*Trabajo realizado con apoyo económico del Instituto de Ecología, A.C. (cuenta 20006), del Consejo Nacional de Ciencia y Tecnología y de la Comisión Nacional para el Conocimiento y Uso de la Biodiversidad.
} 
Se proporcionan descripciones de ambas especies, además de una clave para la identificación de los 12 representantes del complejo de $B$. simaruba hasta ahora conocidos de México y de Centroamérica.

Palabras clave: Bursera, Burseraceae, Centroamérica, México, taxonomía.

\begin{abstract}
One of the taxonomically most difficult groups of the genus Bursera centers around B. simaruba. Several members of this group are often difficult to distinguish from each other and from the very variable $B$. simaruba.

In 1936 Bullock reduced several of these components to synonymy under $B$. ovalifolia (Schltdl.) Engl., because he considered that the proper B. simaruba, the type of which comes from Jamaica, does not exist in Mexico. Later studies, however, showed that many Mexican populations are similar enough to the West Indian plants to be considered members of the same species. Consequently Schlechtendal's epithet became abandoned.

In this contribution $B$. ovalifolia is reinstated for a species characterized by relatively small fruits and leaves with 3 or 5 (rarely 7) leaflets with an abruptly acuminate or cuspidate apex, glabrous or scarcely pubescent, even in their expansion. Its distribution ranges from coastal Jalisco at least to Costa Rica and the trees are particularly abundant in the Oaxacan region of the Tehuantepec Isthmus, where a great diversity of leaflet forms can be observed.

On the other hand, the name B. roseana is proposed for another member of this group, originally described as Terebinthus acuminata, but never legitimately transferred to the genus Bursera. This species grows essentially at altitudes of more than $1200 \mathrm{~m}$, often cohabiting with oaks and pines, and ranging from Nayarit, Zacatecas and Aguascalientes to the State of Mexico and Guerrero.

Descriptions of both species are provided, as well as a key for identification of the 12 members of the B. simaruba complex that are known thus far from Mexico and Central America.
\end{abstract}

Key words: Bursera, Burseraceae, Central America, Mexico, taxonomy.

El acomodo taxonómico de los representantes del género Bursera dista mucho de ser satisfactorio y uno de los grupos de especies que más dificultades han ofrecido para su apropiada delimitación y ubicación es el que se centra alrededor de B. simaruba.

En México y en Centroamérica este conjunto está integrado por árboles con tronco de corteza exfoliante roja o rojiza (variando en ocasiones a café o anaranja- 
da), más bien poco resinosos y aromáticos, cuyas hojas carecen de alas en el raquis, llevan foliolos de margen entero, ápice casi siempre acuminado y tamaño por lo general relativamente grande, las flores se encuentran dispuestas en (pseudo)racimos, no pocas veces a su vez ramificados, las hojas cotiledonares son trilobadas y presentan venación broquidódroma, como lo muestran Andrés-Hernández y EspinosaOrganista (2002).

El carácter monofilético del complejo quedó reafirmado con estudios de secuencia de ADN (Becerra y Venable, 1999; Becerra, 2003) de siete de sus especies (B. arborea, B. attenuata, B. grandifolia, B. instabilis, B. longipes, B. simaruba y Terebinthus acuminata).

Espinosa et al. (2006) propusieron que el grupo de B. simaruba, integrado por las 12 especies que aquí se reconocen para México y Centroamérica, junto con otras 12 antillanas y 2 sudamericanas, se defina como una sección separada del género.

Su componente más conocido y primero en haberse dado a conocer, $B$ simaruba, es un taxon de amplia distribución geográfica, pues se conoce desde el sur de Florida en Estados Unidos a través de prácticamente todas las islas antillanas; en México prospera desde Sonora y Tamaulipas a lo largo de las porciones calientes de ambas vertientes, así como en la península de Yucatán, continuándose su área por Centroamérica y luego en América del Sur hasta Perú y el extremo norte de Brasil.

Es una planta cuya variación morfológica no siempre se entiende y para mayor abundamiento está "rodeada" por un buen número de especies más o menos cercanamente emparentadas que a menudo no son fáciles de diferenciar de la propia B. simaruba ni entre ellas mismas, en particular a nivel de ejemplares aislados de herbario. Los dos casos que a continuación se exponen resultan ilustrativos de esta complicadísima situación.

Schlechtendal (1843, p. 248) dio a conocer Elaphrium ovalifolium con base en material colectado por Schiede en una localidad indefinida de México. La descripción se basa en un ejemplar carente de flores y frutos y reza de la siguiente manera:

E. ovalifolium n. sp., foliis glabris, longe petiolatis, foliolis 3-5, ovalibus, acuminatis, basi obtusis, integerrimis ..., fructibus ...

Rami fusci lenticellis orbicularibus albidis adspersi et cicatricibus fere semirotundis foliorum delapsorum notati sunt. Folia haud magna, petiolus 1 $1 / 2$ poll. et paulo ultra longus, dorso convexus, facie planus, rachis bisulca. Foliolorum petiolus partialis in terminali 3 lin., in lateralibus 1-1 1/2 lin. longus, lamina ovalis s.elliptica fere abrupte acuminata, acumine angusto acutiusculo, interdum curvato, nervus medius paucis pilis patentibus rarius instructus in pagina infera fere concolore prominet, venae minus conspicuae leviter sursum 
arcuatae sub angulo acuto exeuntes marginem leviter revolutum petunt varios in modos anastomosantes. Maxima foliola 2 poll. sunt longa, 8-9 lin. lata. Nec ramificatio inflorescentiae, nec flores fructusque adsunt.

Engler (1883) transfirió la especie a Bursera y posteriormente Rose (1906) la movió a Terebinthus, ambos sin proporcionar datos adicionales a los del protólogo.

Standley (1923) adoptó un concepto inclusivo de su Elaphrium simaruba, en cuya sinonimia integró a E. ovalifolium, así como a algunas otras especies del grupo descritas con anterioridad por Rose. Muy semejante criterio fue adoptado por Bullock (1936), quien consideró a su vez, que la verdadera B. simaruba (cuyo tipo procede de Jamaica) no existe en nuestro país y aceptó el nombre $B$. ovalifolia para todo el conjunto de plantas mexicanas de esta afinidad.

Estudios y avances posteriores permitieron reconocer, sin embargo, que en muchas comarcas de México crecen árboles de morfología suficientemente similar a la de $B$. simaruba para considerarlos como parte de la misma especie. Como consecuencia de tales hallazgos quedó sepultado por varias décadas el uso del binomio B. ovalifolia.

Por otro lado se confirmó también que cabe distinguir un buen número de entidades adicionales de este grupo, de distribución geográfica más restringida, y en tal contexto McVaugh y Rzedowski (1965, p. 354) conjeturaron que B. ovalifolia podría eventualmente corresponder al taxon que de manera provisional habían reconocido como Terebinthus acuminata.

No obstante, la acumulación subsiguiente de nuevas colectas de la vertiente pacífica de México y de Centroamérica ha ido descubriendo la existencia de otra planta diferente, cuyo carácter glabro o casi glabro unido a la presencia de hojas mayormente quinquefolioladas, aunque variables, se ajusta mejor a las precisadas en el protólogo de B. ovalifolia.

Esta especie se distribuye desde la costa de Jalisco hasta Costa Rica y es particularmente común en la región del Istmo de Tehuantepec, penetrando asimismo a la Depresión Central de Chiapas, de donde se dio a conocer a su vez como B. longicuspis Lundell. La fotografía de un isotipo de este último nombre ilustra una planta de foliolos y peciólulos muy similares a los del tipo de B. ovalifolia.

El holotipo de B. ovalifolia, depositado en HAL y examinado por medio de una fotocopia, representa un ejemplar muy fragmentario, consistente de unas ramas y de varios foliolos sueltos que conservan sus peciólulos. Estos últimos, sin embargo, resultan particularmente reveladores, pues son filiformes y miden 10 a $12 \mathrm{~mm}$ de largo (no 2 a 6 mm, como se indica en la descripción original), carácter que en conjunción con los rasgos mencionados en el protólogo (hojas glabras o casi glabras, 3 o 5-folioladas), indica su similitud con la especie que a continuación se describe. 
No es fácil dilucidar de dónde puede provenir el ejemplar tipo de B. ovalifolia. Se sabe que Christian J. W. Schiede colectó en 1828, 1829 y 1830 un gran número de ejemplares de los alrededores de Xalapa y en otras localidades del estado de Veracruz, mismos que envió para su estudio a Diederich F. L. Schlechtendal (Hemsley, 1886-1888, pp. 123-124). Estos materiales llevan por lo general buena información de localidad y a menudo también de características, nombres comunes y usos de las plantas. En fechas posteriores Schiede se estableció en la ciudad de México, donde ejerció medicina hasta su muerte acaecida en 1837. En los últimos años de su vida estuvo particularmente interesado en plantas medicinales, como lo atestiguan varios artículos sobre tal tema publicados en México, y siguió realizando algunas exploraciones botánicas. Así, por ejemplo, se registra que colectó ejemplares de Bursera en el Real de Huautla, Morelos, en Taxco e Iguala, Guerrero y en los alrededores del volcán Jorullo en Michoacán. De allí es posible especular que el de B. ovalifolia procede de la "tierra caliente" de Morelos, Guerrero o Michoacán. Su falta de número, de datos de localidad y de fecha, podría indicar que el ejemplar no fue recogido directamente por Schiede, sino que fue obtenido por intermedio de alguna otra persona.

Dados estos antecedentes, los autores consideran que es razonable el uso del nombre de $B$. ovalifolia para la especie que a continuación se describe, ilustra y discute.

Bursera ovalifolia (Schltdl.) Engl., Bot. Jahrb. 1: 43. 1881. Elaphrium ovalifolium Schltdl., Linnaea 17: 248. 1843. Terebinthus ovalifolia (Schltdl.) Rose, Contr. U.S. Natl. Herb. 10: 121. 1906. Tipo: México, sin localidad precisa, C. J. W. Schiede s.n. (holotipo: HAL). Figs. 1, 3 y 4.

Bursera longicuspis Lundell, Wrightia 3: 3. 1961. Tipo: México, Chiapas, Amatenango del Valle, 1835 m, 12.VI.1945. E. Matuda 5853 (LL, isotipos en MEXU, MO y NY; sus fotografías disponibles en http://www.biosc.utexas.edu.prc.types. html y en http://sciweb.nybg.org/science2/vii2.asp).

Nombres comunes registrados en Oaxaca: mulato, mulato colorado, mulato verde, palo jiote, palo mulato.

Árbol o a veces arbusto hasta de $25 \mathrm{~m}$ de alto, dioico, más bien poco aromático y resinoso; tronco hasta de $45 \mathrm{~cm}$ de diámetro, su corteza externa roja a anaranjada o café-rojiza, exfoliante en tiras delgadas, ramillas glabras desde el inicio de su formación o pronto glabradas, a menudo pruinosas; hojas originándose sobre ramillas de crecimiento nuevo, imparipinnadas o trifolioladas, hasta de $35 \mathrm{~cm}$ de largo y $25 \mathrm{~cm}$ de ancho, peciolo hasta de $9 \mathrm{~cm}$ de largo, raquis sin alas, peciólulos a menudo filiformes, al menos en la juventud, el terminal hasta de $3.5 \mathrm{~cm}$, los latera- 


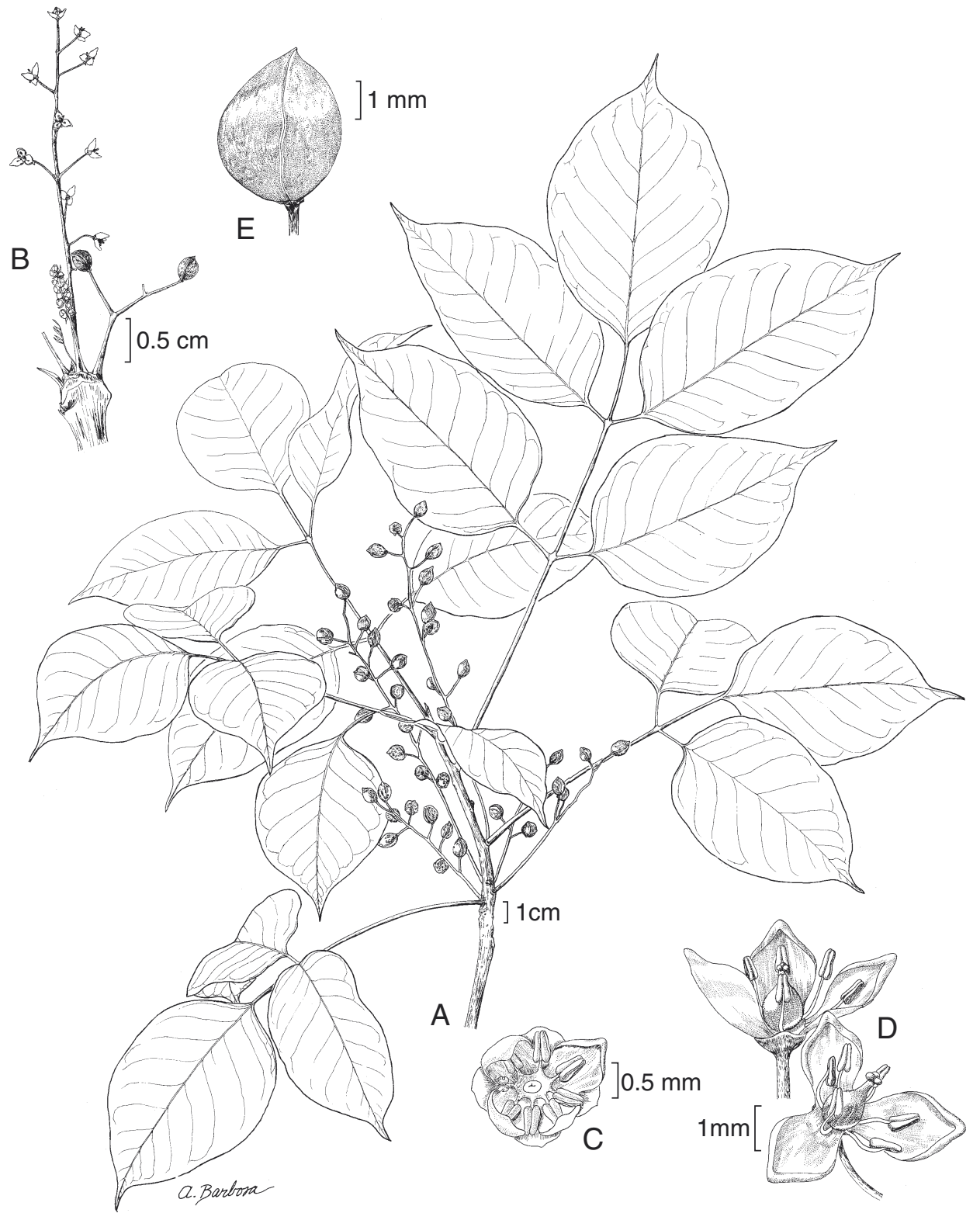

Fig. 1. Bursera ovalifolia (Schltdl.) Engl. A. rama con infrutescencias; B. ramilla con inflorescencia femenina e infrutescencia; C. flor masculina; D. flores femeninas; E. fruto. Ilustrado por Alfonso Barbosa. 
les de (3)6 a $20 \mathrm{~mm}$ de largo, foliolos 3 o 5(7), de forma sumamente variable, por lo común elípticos, ovados o lanceolados, otras veces oblongos, obovados, romboides o casi orbiculares, llegando a ser un poco más anchos que largos, de (1.5)4 a 11(15) cm de largo, de (1)2 a 6(7) cm de ancho, abrupta a muy abruptamente acuminados, caudados o cuspidados en el ápice, cuneados a subcordados en la base, margen entero, con 4 a 12 pares de nervaduras secundarias arqueadas hacia el extremo distal y conformando una nervadura marginal más o menos bien definida, las terciarias formando un retículo, de textura membranácea a cartácea, a menudo brillantes en el haz, un poco más pálidos y opacos en el envés, glabros desde la temprana juventud o a veces con algo de pubescencia en la base del envés; inflorescencias en forma de panículas tirsiformes o piramidales (comunes en las plantas masculinas), o bien, de racimos (más frecuentes en los individuos femeninos), hasta de 15(20) cm de largo, glabras, pedicelos filiformes, de hasta $8 \mathrm{~mm}$ de largo, brácteas lineares a lanceoladas, de ca. $1 \mathrm{~mm}$ de largo, precozmente caducas; flores masculinas pentámeras o rara vez tetrámeras, lóbulos del cáliz anchamente triangulares u ovados, de 0.5 a $0.7 \mathrm{~mm}$ de largo, pétalos elíptico-oblongos, de ca. $2 \mathrm{~mm}$ de largo, cuculados, encorvados en el ápice, blanquecinos o de color crema, filamentos de 1 a $2 \mathrm{~mm}$ de largo, anteras oblongas, de 1 a $1.2 \mathrm{~mm}$ de largo, ovario vestigial o ausente; flores femeninas trímeras, similares a las masculinas, pero con los pétalos un poco más anchos, anteras de los estaminodios de ca. $0.6 \mathrm{~mm}$ de largo, ovario trilocular, estilo de ca. $0.2 \mathrm{~mm}$ de largo, estigmas 3; infrutescencia hasta de $10 \mathrm{~cm}$ de largo, por lo general racemosa, pedúnculos y pedicelos ligeramente engrosados, estos últimos hasta de $11 \mathrm{~mm}$ de largo; fruto trivalvado, globoso u ovoide, ligeramente triquetro, de 6 a 8(9) mm de largo, rojizo en la madurez, glabro, hueso de 6 a $8 \mathrm{~mm}$ de largo, totalmente cubierto por un pseudoarilo pálido.

Especie distribuida desde Jalisco hasta Costa Rica (Fig. 2), aunque es factible que su área se extienda en realidad hasta el norte de Sudamérica.

A este respecto cabe apuntar el hecho de que el espécimen isotipo de Bursera bonairensis Boldingh (I. Boldingh 6548 (K)), procedente de la isla Aruba ubicada frente a la costa de Venezuela, presenta substanciales semejanzas con B. ovalifolia en la morfología de las hojas. Aunque en el protólogo correspondiente se describen estas últimas como 3 o 5-yugadas, el mencionado ejemplar de Kew muestra 3 hojas trifolioladas (además de 9 foliolos sueltos). Todos los foliolos se caracterizan por el ápice caudado o cuspidado.

Habitante del bosque tropical caducifolio y subcaducifolio en altitudes de 0 a 1500 (1850) m. Florece en mayo y en junio, permanece sin follaje de noviembre a mayo. 
Acta Botanica Mexicana 81: 45-70 (2007)

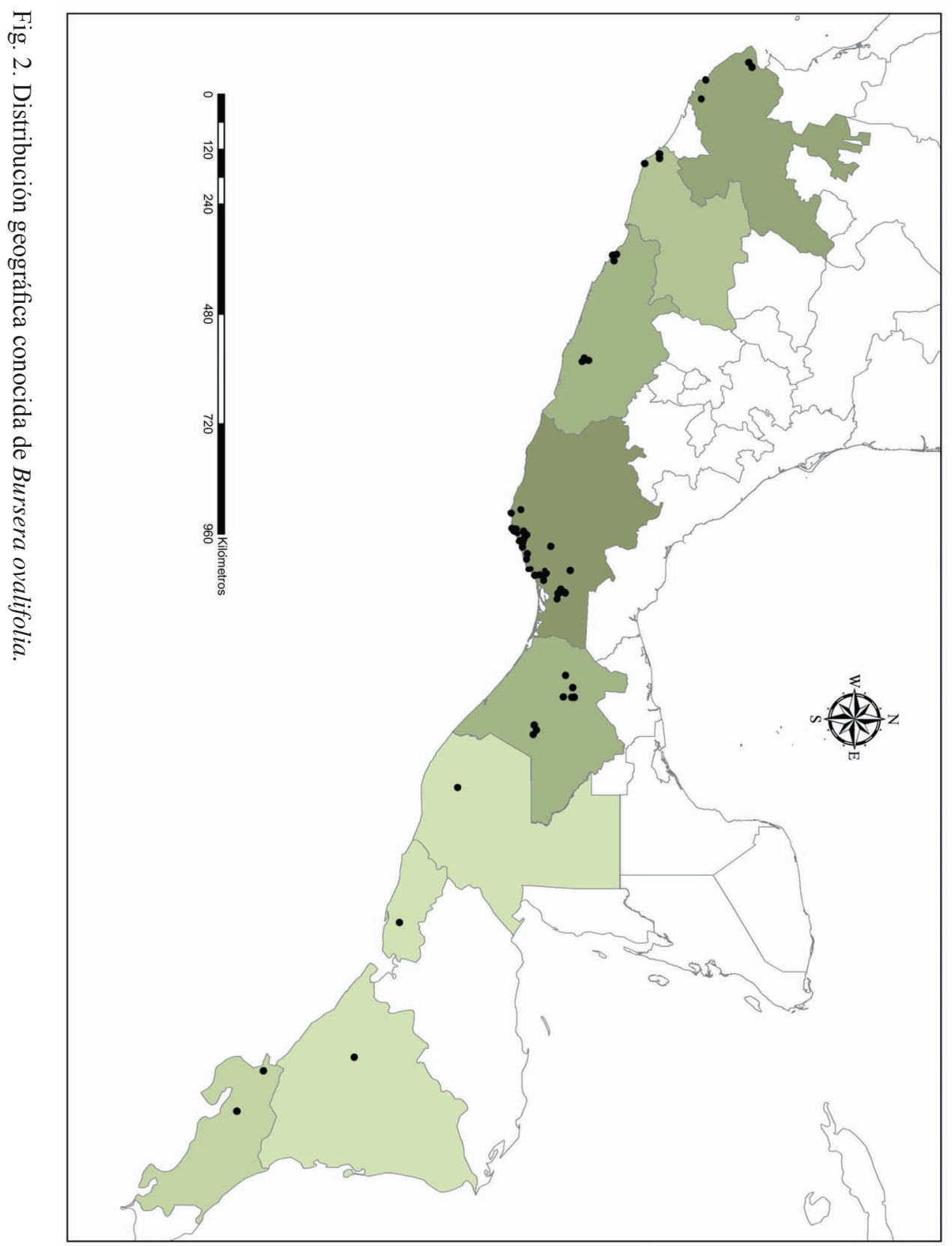


Materiales examinados.

MÉXICO, Jalisco: $29 \mathrm{~km} \mathrm{~N}$ of Melaque on highway $80 \mathrm{~N}$ of Barra de Navidad, A. C. Gibson \& N. MacCarten 3393 (IEB, MEXU); Estación de Investigación, Experimentación y Difusión Chamela UNAM, municipio de La Huerta, J. A. S. Magallanes 3807 (ENCB, IEB); 7.9 km al W de El Tuito, camino a Ixtlahuahuey, camino a Cabo Corrientes, municipio de Cabo Corrientes, P. Magaña R. 355 (MEXU); 28 km al SW de Puerto Vallarta, sobre la carretera a El Tuito, J. Rzedowski 37766 (IEB).

Michoacán: 6 km al W de Maruata carretera Tecomán, Col. Playa Azul, municipio de Aquila, E. Martínez Salas et al. 4531 (MEXU); 8 km antes de Aquila, dirección Playa Azul - Aquila, 18³5'5.3" N, 103³3'3.5" O, R. Medina Lemos et al. 4279 (MEXU); Cruz de Campos, municipio de Aquila, J. Rzedowski et al. s.n., 21.VI.1982 (IEB).

Guerrero: Tierra Colorada (ciudad), M. Blanco et al. 769 (ENCB); cerro al $\mathrm{S}$ de Ixtapa (Zihuatanejo), M. Blanco y C. Toledo 774 (MEXU); km 3 de la carretera Zihuatanejo - Ixtapa, M. Blanco et al. 777 (ENCB); $800 \mathrm{~m}$ al SO del caserío

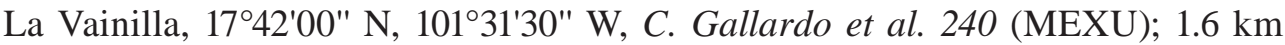
SO del caserío La Vainilla, cerros que limitan la Mesa del Mango, C. Gallardo 711 (MEXU); Tepeguaje, cerro Alto Tepeguaje, H. Kruse 2592 (ENCB, MEXU), 2872 (IEB, MEXU), 2879 (IEB, MEXU), 2906 (IEB, MEXU), 2908 (IEB, MEXU), 2909 (IEB, MEXU), 2947 (IEB, MEXU); 11 km carretera Zihuatanejo - Lázaro Cárdenas, R. Medina Lemos et al. 4050 (MEXU); 15 km carretera Zihuatanejo - Lázaro Cárdenas, después del puente Salinas, R. Medina Lemos et al. 4053 (MEXU); arriba Mirador, carretera Acapulco a Puerto Marqués, F. Miranda 9304 (MEXU); 6 km al E de Tierra Colorada, sobre la carretera a Ayutla, J. Rzedowski 35839 (ENCB, MEXU), 36712 (ENCB).

Oaxaca: Distrito JuchitÁn: Pedrera de Mazahua, a $6.5 \mathrm{~km}$ en línea recta al SE (106 ) de Nizanda, 16³8'21" N, 9456'38" O, municipio de Asunción Ixcaltepec, C. Gallardo y A. Pérez-García 1438 (IEB), 1528 (IEB); (cerro de la "Piedra Azul") a $1.0 \mathrm{~km}$ en línea recta al NE (32) de Nizanda, 16³9'53" N, 950'26" O, municipio de Asunción Ixcaltepec, C. Gallardo y A. Pérez-García 1480 (IEB), 1528 (MEXU); ibid., A. Pérez-García y B. Reyes Ríos 1136 (IEB); alrededores de la vía del tren transístmico, a $3.2 \mathrm{~km}$ en línea recta al NO $\left(330^{\circ}\right)$ de Nizanda, 160 40'00" N, 9501'17" O, municipio de Asunción Ixcaltepec, C. Gallardo y A. Pérez-García 1864 (IEB); $2.11 \mathrm{~km}$ (LR) al ESE de La Mata, 16³6'43.9" N, 9457'29.4" W, municipio de Asunción Ixcaltepec, S. H. Salas M. 4683 (IEB, MEXU); 2.15 km (LR) al noreste de La Mata, 16³6'44.7" N, 9457'23.3" W, municipio de Asunción Ixcaltepec, A. Saynes et al. 3049 (IEB, MEXU); 4.06 km al este de La Mata, 16³5'39" N, 9453'32.9" W, municipio de Asunción Ixcaltepec, A. Saynes et al. 3082 (MEXU); 2.55 km en línea 
recta al SW de Cieneguita, 1644'35.3" N, 9458'3.4" W, municipio de Asunción Ixcaltepec, A. Saynes et al. 3182 (IEB); 1.31 km (LR) NE (68º) de La Mata, 16³4'20.7" N, 9457'54.6" W, municipio de Asunción Ixcaltepec, A. Saynes 3267 (IEB, MEXU); ladera N del cerro Timbón, 3.63 km (LR), 22 de Chivela, 16²44'36" N, 9454'10.3" W, A. Saynes y A. Sánchez Martínez 3506 (IEB, MEXU); 2.04 km (LR) $110^{\circ}$ de La Mata, 16³6'41.5" N, 9757'30.1" W, municipio de Asunción Ixcaltepec, A. Saynes y A. Sánchez Martínez 3558 (IEB, MEXU). Distrito Pochutla: vereda de Aguaje Anonas, 1546'26" N, 96²'57.2" W, municipio de Santa María Huatulco, G. Juárez García et. al. 2197 (IEB); $300 \mathrm{~m}$ al este de río Cacaluta, $500 \mathrm{~m}$ al sur de la carretera costera No. 200, 15²6'24.5" N, 96¹0'26.6" W, municipio de Santa María Huatulco, G. Juárez García et al. 2230 (IEB); rumbo a la playa Riscalillo, a 1 km de la playa San Agustín, 15²41'56.8" N, 96²13'40.7" W, municipio de Santa María Huatulco, G. Juárez García et al. 2681 (IEB); a 3 km al E de San Miguel del Puerto, camino a Xadani, 1554'46" N, 96²'59" W, municipio de San Miguel del Puerto, E. Martínez Salas et al. 32347 (IEB); a $152 \mathrm{~m}$ en LR al sur de la estación de campo marítima del Parque Nacional Huatulco, en un extremo de la playa Cacaluta, 1543'11.3" N, 96¹0'6.7" W, municipio de Santa María Huatulco, A. Nava Zafra et al. 749 (IEB); $1.8 \mathrm{~km}$ de Xadani al Achiote, municipio de San Miguel del Puerto, J. Pascual 81 (IEB, MEXU); camino a Tepesco, municipio de San Miguel del Puerto, J. Pascual 461 (IEB); cerro Campana, municipio de San Miguel del Puerto, J. Pascual 1108 (IEB); Llano de Horno, 1559'14.3" N, 96 5'44.3" W, municipio de San Miguel del Puerto, J. Pascual 1459 (IEB); Oreja de León, 15¹8'38.2" N, 96'18.4" W, municipio de San Miguel del Puerto, J. Pascual 1474 (IEB); camino a la estación de campo El Sabanal, 1546'42.5" N, 96¹1'56.8" W, municipio de Santa María Huatulco, S. H. Salas M. et al. 5897 (IEB); camino viejo a Santa María Huatulco, adelante de la estación de campo El Sabanal, 1546'1.6" N, 96¹1'34.4" W, municipio de Santa María Huatulco, S. H. Salas M. et al. 5923 (IEB); inicio de la playa El Maguey, 15²4'58.9" N, 96²'57.7" W, municipio de Santa María Huatulco, A. Sánchez Martínez y A. Nava 138 (IEB); $500 \mathrm{~m}$ al este del río Cacaluta, camino al muestreo 4 de G. Juárez, 1544'38.3" N, 96¹0'31.1" W, municipio de Santa María Huatulco, A. Sánchez Martínez et al. 1455 (IEB); este del río Cacaluta, muestro 4 de G. Juárez, 1544'42.6" N, 96¹0'33" W, municipio de Santa María Huatulco, A. Sánchez Martínez et al. 1469 (IEB); Bahía Riscalillo, 1541'49.7" N, 96³'32.3" W, municipio de Santa María Huatulco, A. Saynes V. y A. Sánchez Martínez 4440 (IEB); .510 km de carretera a Cacaluta, 5ㄴR, $15^{\circ} 44^{\prime} 42.9^{\prime \prime} \mathrm{N}, 9^{\circ} 9^{\prime} 5.5^{\prime \prime} \mathrm{W}$, municipio de Santa María Huatulco, A. Saynes et al. 5632 (IEB); Mazmita, 2 km E, 1540'8" N, 96³1'58" W, municipio de Santa María Tonameca, E. Torres B. et al. 1425 (IEB). Distrito Tehunantepec: Barra de la Cruz, 0.5 km NW de la desviación, 1551'9" N, 9559'3" W, municipio de Santiago Astata, M. Elorsa 1137 (MEXU); $2 \mathrm{~km}$ al oeste de Barra de la Cruz, sobre lomas del cerro Portillo, 1550'15.9" N, 9558'43" W, municipio de Santiago Astata, $M$. 
Elorsa 4816 (IEB, MEXU); $300 \mathrm{~m}$ al N de la desviación a Barra de la Cruz, 1550'59.4" N, 9558'51.3" W, municipio de Santiago Astata, M. Elorsa 6097 (IEB); $100 \mathrm{~m}$ al este del puerto Sta. María, 1559'53.9" N, 95²4'54.7" W, municipio de San Pedro Huamelula, M. Elorsa 6178 (IEB, MEXU); cerro Guiengola, T. MacDougall s.n., 24.V.1971 (ENCB); ibid., M. L. Torres et al. 117 (IEB, MEXU); cerca de la cumbre de El Cerro Marimba, al N de Rincón Bamba, municipio de Salina Cruz, C. Martínez R. 606 (IEB, MEXU); cerro Pozo Zorrillo, km 245 carr. Cristóbal Colón de Tehuantepec a Oaxaca, C. Martínez R. 690 (IEB, MEXU); Barra de la Cruz, $15^{\circ} 50^{\prime 2} 23^{\prime \prime}$ N, 9558'14" W, municipio de Santiago Astata, E. Martínez S. et al. 32497 (IEB), 32498 (MEXU); Tehuantepec, E. Matuda 691 (MEXU); Barra de la Cruz, 2.5 km WNW LR, cerro enfrente al $\mathrm{N}$ del Portillo, dominando la carretera costera, 1550'41" N, 9559'35" W, municipio de Santiago Astata, C. Perret et al. 397 (IEB); Zaachilac, $10 \mathrm{~km} \mathrm{~W}$, cascada de La Tortolita, 1559'7" N, 95³7'26" W, municipio de Santiago Astata, C. Perret et al. 598 (IEB); Rincón Bamba, 0.7 km de la desviación a Concepción Bamba, municipio de Tehuantepec, 16¹'16" N, 95²5'14" W, J. Rivera et al. 1846 (IEB, MEXU), ibid., S. Salas et al. 2207 (IEB, MEXU); cerro Guiengola, municipio de Santo Domingo Tehuantepec, A. Reyes García et al. 2815c (MEXU); 15 km al NW de Tehuantepec, sobre la carretera a Jalapa de Márquez, J. Rzedowski 38122 (IEB); cerca de Santiago Astata, 74 km al W de Salina Cruz, J. Rzedowski 38138 (IEB); cerca de Rincón Bamba, 39 km al W de Salina Cruz, J. Rzedowski 38140 (IEB); Rincón Bamba, 0.7 km E de la desviación a Concepción Bamba, 16¹'16" N, 95²5'14" W, S. H. Salas 2084 (MEXU); Barra de la Cruz, 4 km NE RL, ladera arriba del puente del Ciruelo, municipio de Santiago Astata, S. H. Salas 2341 (MEXU); cascada La Tortolita, 1558'59.7" N, 95³7'23.2" W, municipio de Santiago Astata, S. H. Salas M. 3198 (IEB, MEXU); rancho Zimatán, 1556'22" N, 96¹'30" W, municipio de Santiago Astata, S. H. Salas 3951 (MEXU); San Isidro Chacalapa, pueblo, 1555'30" N, 9556'15" W, municipio de San Pedro Huamelula, S. H. Salas et al. 5971 (IEB); cerro Cedro, a $760 \mathrm{~m}$ (LR) al NW del punto que se encuentra a 1.5 km de la brecha a Chacalapa, 1553'23.6" N, 9556'15.1" W, municipio de Santiago Astata, A. Saynes et al. 2406 (IEB, MEXU); $1.8 \mathrm{~km}$ del centro de Barra de la Cruz, rumbo al río Zimatán, 1549'38.9" N, 9558'15.4" W, municipio de Santiago Astata, A. Saynes et al. 3014 (MEXU); ruinas del cerro Guiengola, M. L. Torres et al. 50 (IEB, MEXU); ladera S del cerro Guiengola, M. L. Torres et al. 144 (IEB, MEXU); “Arroyo de Piedra”, ladera oeste, entrando por El Mármol, cerro Guiengola, M. L. Torres et al. 227 (IEB, MEXU); ladera oriente del cerro Guiengola, M. L. Torres et al. 405 (MEXU); ladera S del cerro Guiengola, entrando por Paso Alicia, $14 \mathrm{~km}$ al NW de Tehuantepec, M. L. Torres et al. 428 (IEB, MEXU); Las Ruinas y Las Grutas, $1 \mathrm{~km}$ al $\mathrm{N}$ de las ruinas del cerro Guiengola al NW de Tehuantepec, $16^{\circ} 21^{\prime} \mathrm{N}$, 95¹9’ W, M. L. Torres et al. 439 (MEXU); subida a las ruinas del cerro Guiengola, M. L. Torres et al. 917 (IEB, MEXU); cerro Guiengola, al NW de Tehuantepec, $R$. 
Torres C. y J. L. Villaseñor 5128 (IEB, MEXU); cerro Guiengola, N de Tehuantepec, $R$. Torres et al. 5317 (MEXU); Rincón Bamba, municipio de Salina Cruz, R. Torres y C. Martínez R. 8346 (MEXU), 8350 (MEXU); El Limón, 11 km al SSE de Jalapa del Márques, I. Trejo 1330 (MEXU); Rincón Bamba, municipio de Salina Cruz, $R$. Torres C. y C. Martínez 8346 (IEB), 8350 (IEB). Distrito Yautepec: 20 km al NW de La Reforma, sobre el camino a Oaxaca, municipio de Asunción Tlacolulita, $J$. Rzedowski 38121 (IEB).

Chiapas: 6-8 km east of Frontera Comalapa along road to Cd. Cuauhtemoc, municipio of Frontera, D. E. Breedlove 39042 (MEXU); Cañón Sumidero a kilómetro 14.5, municipio de Tuxtla Gutiérrez, C. Brown MacVean 27 (IEB); road from Tuxtla Gutierrez to Chicoasén, Mirador Manos que Imploran, municipio de San Fernando, R. J. Hampshire et al. 1109 (MEXU), 1125 (MEXU); Trapichito, Comitán, E. Matuda 5758 (MEXU); $1 \mathrm{~km}$ al SE del entronque Tzimol - Uninajab, camino a Uninajab, $16^{\circ} 08^{\prime} 00^{\prime \prime} \mathrm{N}, 92^{\circ} 11^{\prime} 44^{\prime \prime} \mathrm{W}$, municipio de Tzimol, A. Reyes García 486 (IEB, MEXU), 1123 (MEXU); ibid., A. Reyes García y G. Urquijo 843 (MEXU); Mirador, Manos que Imploran, $10 \mathrm{~km}$ SW de Chicoasén, A. Reyes García y G. Urquijo 881 (MEXU), 956 (MEXU); 8 km al SE de Tzimol, sobre la desviación a Uninajab, municipio de Comitán, A. Reyes García et al. 1811 (IEB, MEXU); 1 km al NW del entronque aeropuerto - Ocozocuautla - México, sobre la carretera México 190, municipio de Ocozocuautla, A. Reyes García y R. Hampshire 1938 (IEB, MEXU); 6 km al N de Soyaló, sobre la carretera a Bochil, J. Rzedowski 33179 (ENCB), 33181 (ENCB), 33636 (ENCB, MEXU); Soyaló en el poblado, C. Toledo et al. 175 (MEXU); mirador La Coyota, Parque Nal. El Sumidero, municipio de Tuxtla Gutiérrez, C. Toledo et al. 186 (IEB, MEXU), 187 (MEXU).

GUATEMAla: Departamento Sololá, Bahía de Pasanahí, $6 \mathrm{~m}$ de la orilla del lago, municipio de Atitlán, E. Duarte 82.312 (MEXU).

EL SALVADOR: Usulatán, Laguna Alegría, Volcán Alegría, 88²9'43" W, 132'ㄱ' $36^{\prime \prime}$ N, A. K. Monro et al. 3023 (IEB).

NICARAGUA: Departamento de Boaco, San José de Los Remates, "La Majada”, 12³7' N, 8551' W, P. P. Moreno 16294 (MEXU).

COSTA RICA: Puntarenas: Monteverde cliff edge on Pacific slope, Bajo Tigre trail, 10¹8' N, 8448' W, cantón de Puntarenas, W. Haber y W. Zuchowski 10091 (IEB).

Guanacaste: Santa Rosa National Park, 30 km north-west of Liberia, ca. $10^{\circ} 50^{\prime} \mathrm{N}, 8^{\circ} 35^{\prime} \mathrm{W}$, D. H. Janzen 11870 (ENCB).

Bursera ovalifolia es una entidad marcadamente variable en cuanto a la forma y al tamaño de los foliolos se refiere (Fig. 3). Con más frecuencia estos últimos se observan elípticos a ovados, su ápice es abruptamente acuminado y miden 4 a $8 \mathrm{~cm}$ 

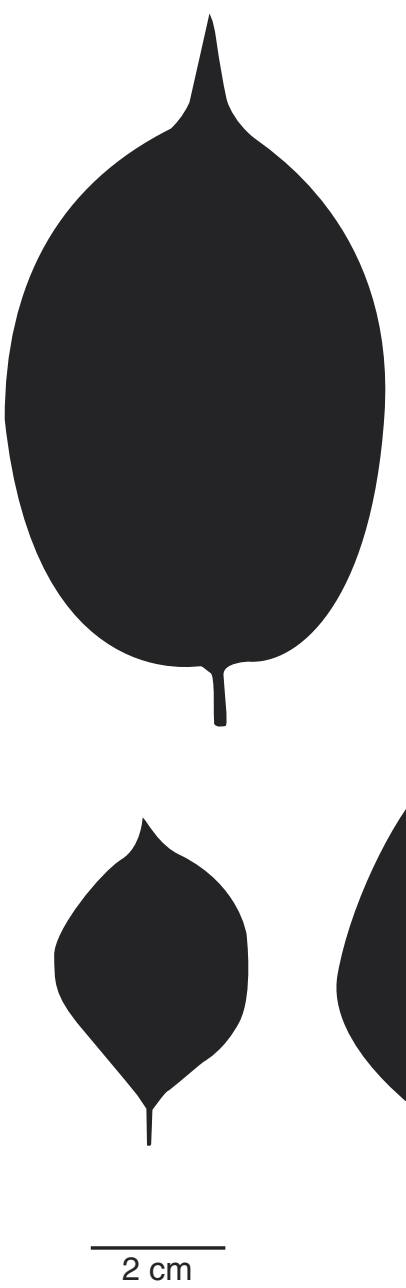
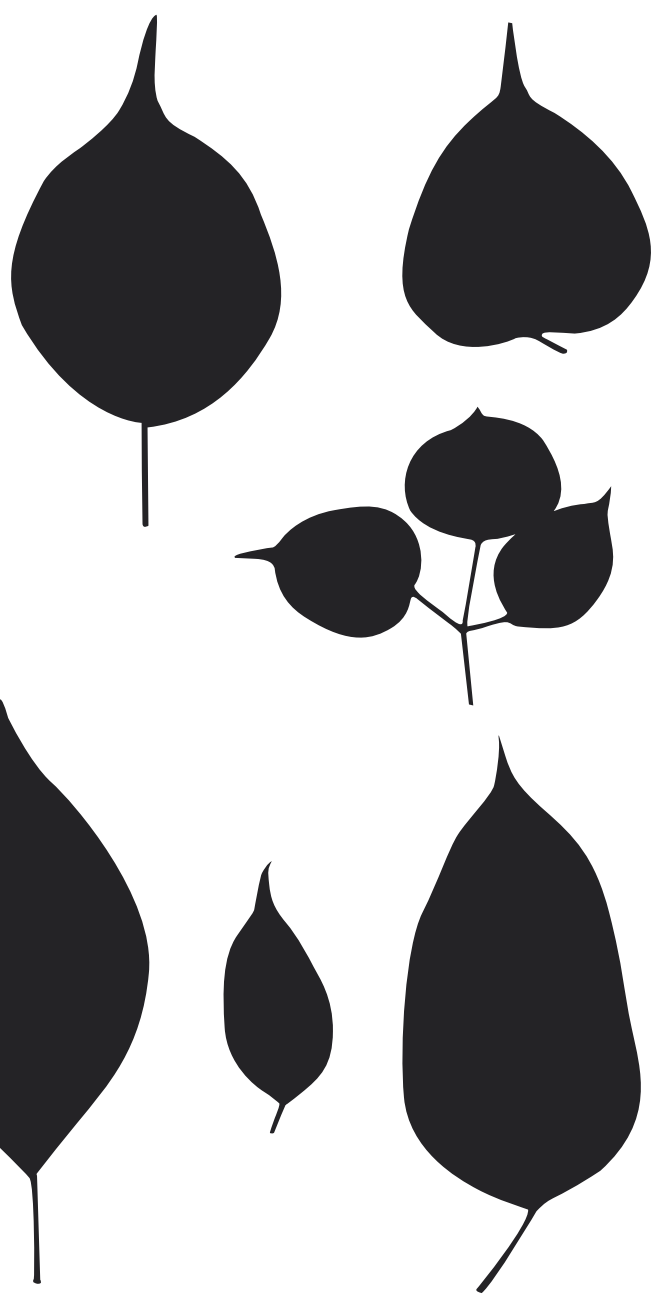

Fig. 3. Siluetas mostrando algunos ejemplos de la variabilidad de forma y de tamaño de los foliolos de Bursera ovalifolia.

de largo. Sin embargo, en varias poblaciones del Istmo de Tehuantepec de Oaxaca y también de Costa Rica, algunos o todos los foliolos llegan a ser suborbiculares y no pasan de $5 \mathrm{~cm}$ de diámetro, a menudo llevando una angosta cauda terminal hasta de $2 \mathrm{~cm}$ de largo. Es tan diferente el aspecto de las hojas de estas plantas que sólo con ayuda de una larga serie de ejemplares de carácter intermedio pudo entenderse que se trata de la variación continua de una sola especie. 
En la región costera de Oaxaca no escasean individuos con foliolos hasta de $15 \mathrm{~cm}$ de longitud y $7 \mathrm{~cm}$ de anchura. El número de foliolos por lo general es de 3 y 5 , en pocos casos todos son de 3 , en otros algunas hojas llevan 7.

La especie definitivamente pertenece al complejo de B. simaruba y difiere de esta última y de $B$. roseana en los frutos más pequeños, ubicados sobre pedicelos menos engrosados, en combinación con hojas glabras (o casi glabras) que llevan comúnmente 3 o 5 foliolos por lo general membranáceos en la madurez (Fig. 4). Se distingue de $B$. cinerea, de B. roseana, así como de B. krusei y B. permollis en la falta o escasez de la pubescencia.

B. ovalifolia es morfológicamente muy semejante a B. standleyana, descrita de un bosque húmedo próximo al litoral pacífico de Costa Rica, y sólo conocida de aquel país. Esta última corresponde a un árbol epifítico que se colectó con hojas, flores femeninas y frutos tiernos en el mes de febrero. Se requerirá de estudios comparativos detallados para definir las relaciones entre las dos especies.

Otro componente mexicano del grupo de B. simaruba fue descrito por Rose (1909) bajo el nombre de Terebinthus acuminata, con base en un ejemplar procedente de Jalisco. Pocos años después (Rose, 1911) el mismo autor transfirió esta especie a Elaphrium y Engler (1931) estableció la combinación Bursera acuminata, sin reparar que tal binomio ya había sido usado por Willdenow en 1806 para una planta diferente.

A su vez Standley (1923) ubicó a Elaphrium acuminatum en la sinonimia de E. simaruba y en ello fue seguido por Bullock (1936) quien, partiendo de la opinión (ya referida en la pág. 48 de este artículo) de que B. simaruba no existe en México, revivió para todo el conjunto el nombre de $B$. ovalifolia.

No obstante, McVaugh y Rzedowski (1965) reconocieron, al menos tentativamente, la existencia de una serie de poblaciones, tanto en Jalisco, como en Michoacán y en el Estado de México, que corresponden al tipo de Rose y que muestran consistencia en sus atributos diferenciales respecto a B. simaruba. Se trata de árboles de estatura por lo común baja y que viven por lo general en altitudes superiores a $1200 \mathrm{~m}$, a menudo en colindancia con encinares y pinares. Por otro lado, sin embargo, $T$. acuminata no discrepa mucho en su morfología de $B$. attenuata, especie mayormente conocida de altitudes inferiores a 1000 m de Nayarit y Sinaloa, y en tal circunstancia los mencionados autores (1965) optaron por dejar pendiente la realización de los cambios nomenclaturales necesarios, a reserva de que ulteriormente se averiguara con más precisión si realmente se trata de dos taxa distintos.

En las cuatro décadas que ya han transcurrido desde la publicación del citado trabajo cabe resaltar los siguientes aportes a este dilema. Los análisis basados en secuencias de ADN (Becerra y Venable, op. cit., Becerra, op. cit.) confirman la cercana relación entre las dos entidades, pero no proporcionan suficientes elementos 
Rzedowski et al.: Restauración de Bursera ovalifolia y nombre nuevo para Terebinthus acuminata
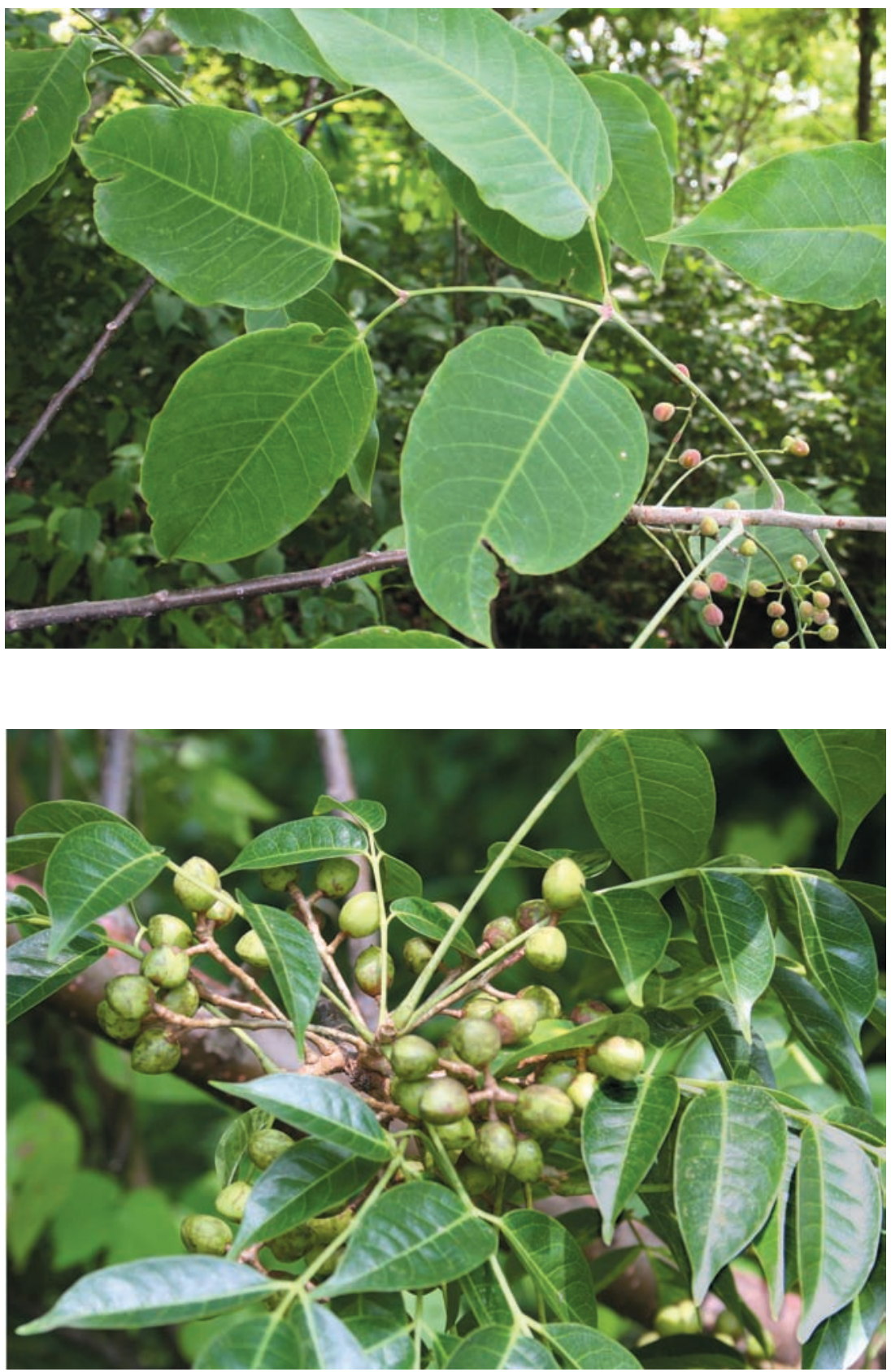

Fig. 4. Ramillas de Bursera ovalifolia (arriba) y de B. simaruba (abajo). 
para ayudar a definir su recíproca situación taxonómica. La acumulación de colectas nuevas ha permitido ampliar la distribución geográfica conocida de ambas, sin dejar de conservar sus diferencias ecológicas correlacionadas con las morfológicas, que no trascienden mucho más allá de la disimilitud en la repartición de la pubescencia de las hojas. En una localidad de Jalisco algunos individuos de T. acuminata parecen llevar cierta influencia genética de B. attenuata.

Por otro lado, sin embargo, la profundización del conocimiento que se ha estado obteniendo acerca de todo el conjunto de los "satélites" de B. simaruba ha ido mostrando con cada vez más claridad que la distribución espacial (y también temporal) del indumento posee una singular trascendencia en la diferenciación de los componentes de este grupo de plantas. Así, se puede apreciar ahora que el carácter no solamente define y separa notablemente a B. grandifolia, B. longipes, B. permollis y B. arborea, sino también a B. krusei, B. standleyana, B. cinerea y B. ovalifolia. La única especie en que el rasgo parece carecer de similar importancia es la propia B. simaruba, cuyas poblaciones muestran una manifiesta variación en la presencia y en la repartición de la pubescencia, difícil de correlacionar con la distribución geográfica y ecológica de sus poblaciones.

Tales antecedentes y enfoques sugieren la conveniencia de aceptar a Terebinthus acuminata como taxon independiente y en consecuencia se propone la siguiente modificación de su nomenclatura.

Bursera roseana Rzed., Calderón \& Medina, nom. nov. Terebinthus acuminata Rose, Contr. U.S. Natl. Herb. 12: 278. 1909. Elaphrium acuminatum (Rose) Rose, North Amer. Fl. 25: 247. 1911. Bursera acuminata (Rose) Engl., Natur. Pflanzenfam. ed. 2. 19a: 425. 1931, non B. acuminata Willd., 1806. Tipo: México, Jalisco: near Chapala, 5.X.1903, J. N. Rose y J. H. Painter 7656 (holotipo US!, isotipo en NY; fotografías disponibles en http://ravenel.si.edu/botany/types/jstaxa/typeFrames.cfm y en http://sciweb.nybg.org/science2/vii2.asp). Fig. 5.

Nombres comunes: copal, papelillo.

Árbol hasta de 12(20) m de alto, aparentemente dioico, más bien poco aromático y resinoso; tronco hasta de $25 \mathrm{~cm}$ de diámetro, su corteza exfoliante en tiras delgadas, rojas, anaranjadas o café-rojizas, ramillas tiernas a menudo densamente vilosas al principio, pero perdiendo rápidamente todos o casi todos los pelos, otras veces glabras desde el principio; hojas originándose sobre ramillas de crecimiento nuevo, imparipinnadas, hasta de $45 \mathrm{~cm}$ de largo y $22 \mathrm{~cm}$ de ancho, peciolo hasta de $12 \mathrm{~cm}$ de largo, raquis sin alas, peciólulo terminal hasta de $4 \mathrm{~cm}$ de largo, los laterales de 1 a $9 \mathrm{~mm}$ de largo, de $1 \mathrm{~mm}$ o un poco más de ancho, foliolos (3) 5 a 7(9), ovados a elípticos, el terminal a veces obovado o subrómbico, de 4.5 a $15 \mathrm{~cm}$ 
Rzedowski et al.: Restauración de Bursera ovalifolia y nombre nuevo para Terebinthus acuminata

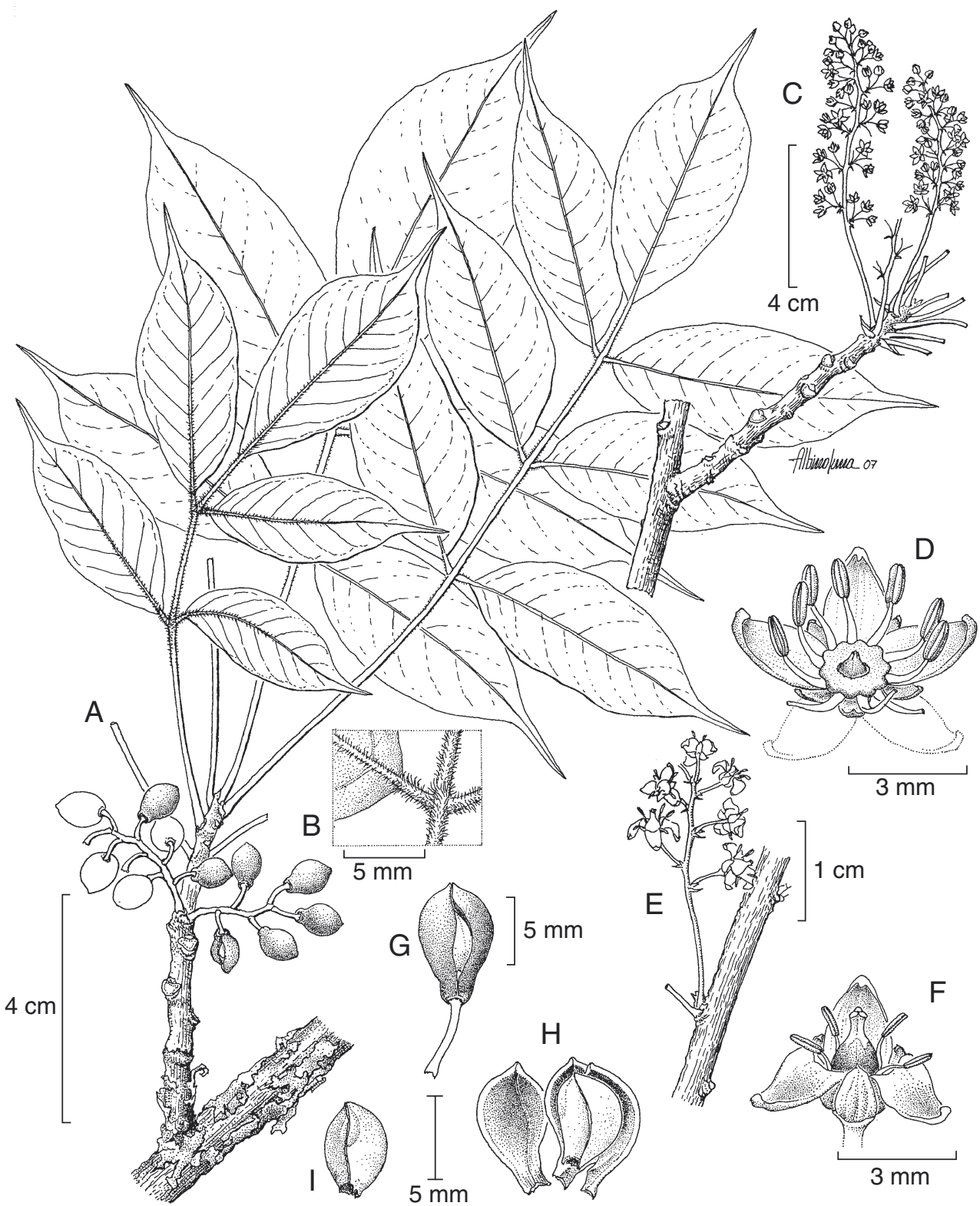

Fig. 5. Bursera roseana Rzed., Calderón \& Medina. A. rama con hojas y frutos; B. detalle de la pubescencia de la hoja; C. rama con inflorescencias masculinas; D. flor masculina; E. rama con inflorescencia femenina; F. flor femenina; G. fruto; H. fruto abierto; I. hueso. Ilustrado por Albino Luna. 
de largo, de 2 a 6 cm de ancho, ápice abrupta y largamente acuminado, base cuneada a truncada, a menudo inequilátera, margen entero, nervaduras secundarias 5 a 12 pares, arqueadas, las terciarias formando un retículo, de textura membranácea o cartácea, brillantes y glabros a casi glabros desde la juventud en el haz, opacos y pilosos o pilósulos sobre las nervaduras en el envés, al menos en la juventud, a veces completamente glabros en la madurez; inflorescencias en forma de panículas piramidales angostas (a veces las femeninas reducidas a racimos), hasta de $13 \mathrm{~cm}$ de largo y $5 \mathrm{~cm}$ de diámetro, glabras, brácteas lineares a lanceoladas, de 1.5 a $2 \mathrm{~mm}$ de largo, caedizas, pedicelos filiformes, hasta de $8 \mathrm{~mm}$ de largo; flores masculinas pentámeras o a veces tetrámeras, segmentos del cáliz triangulares, de poco menos de $1 \mathrm{~mm}$ de largo, pétalos elíptico-oblongos, de 2 a $2.5 \mathrm{~mm}$ de largo, cuculados y encorvados en el ápice, blanquecinos o verdosos, filamentos de ca. $1.5 \mathrm{~mm}$ de largo, anteras oblongas, de ca. $1 \mathrm{~mm}$ de largo, ovario vestigial; flores femeninas trímeras o a veces tetrámeras, similares a las masculinas, anteras de los estaminodios de ca. 0.5 $\mathrm{mm}$ de largo, ovario trilocular, estilo muy breve, estigma trilobado; frutos triquetro-ovoides, de 9 a $12 \mathrm{~mm}$ de largo, glabros, sostenidos por pedicelos notablemente engrosados, huesos de 7 a $9 \mathrm{~mm}$ de largo, totalmente rodeados por el pseudoarilo pálido.

Especie propia del bosque tropical caducifolio, frecuentemente en colindancia o en convivencia con encinares y pinares, en altitudes de (600)1200 a 1900 m. Conocida de Nayarit, Zacatecas, Aguascalientes, Jalisco, Colima, Michoacán, Estado de México y Guerrero (Fig. 6). Florece en mayo y en junio. Permanece sin follaje de noviembre a mayo.

Material examinado:

Zacatecas: road from Jalpa to Aguascalientes via Calvillo, 3.5 miles east of Jalpa, at km 86, W. R. Anderson y C. Anderson 5278 (ENCB); 8 km al S de Moyahua, sobre la carretera a Guadalajara, J. Rzedowski 29362 (ENCB).

Aguascalientes: sureste de la barranca Tres Cruces, 2147'41" N, 102 $51^{\circ} 06^{\prime \prime}$ W, municipio de Calvillo, M. de la Cerda 7273 (HUAA); cañada Arroyo Hondo, municipio de Calvillo, M. de la Cerda y G. García 1586 (HUAA); presa de Los Serna, municipio de Calvillo, G. García R. 3429 (HUAA); $2.7 \mathrm{~km}$ al sur de la presa Los Serna, municipio de Calvillo, G. García R. 4776 (HUAA).

Nayarit: 17.3 km al NW de Jesús María, camino Jesús María - La Mesa del Nayar, en Cañada del Nogal, $22^{\circ} 13^{\prime}$ N, $104^{\circ} 35^{\prime \prime}$ W, municipio de Nayar, G. Flores y $P$. Tenorio 1323 (ENCB, MEXU); 17 km al N de Jesús María, camino Jesús María - La Mesa del Nayar, $22^{\circ} 15^{\prime} \mathrm{N}, 104^{\circ} 35^{\prime} \mathrm{W}$, municipio de Nayar, G. Flores y $R$. Ramírez 2164 (MEXU); brecha al Cuarenteño, entronque carretera Peñitas - San Blas, 21³1'10.8" N, 10458'16.6" W, R. Medina Lemos et al. 3405 (MEXU), 3406 
Rzedowski et al.: Restauración de Bursera ovalifolia y nombre nuevo para Terebinthus acuminata

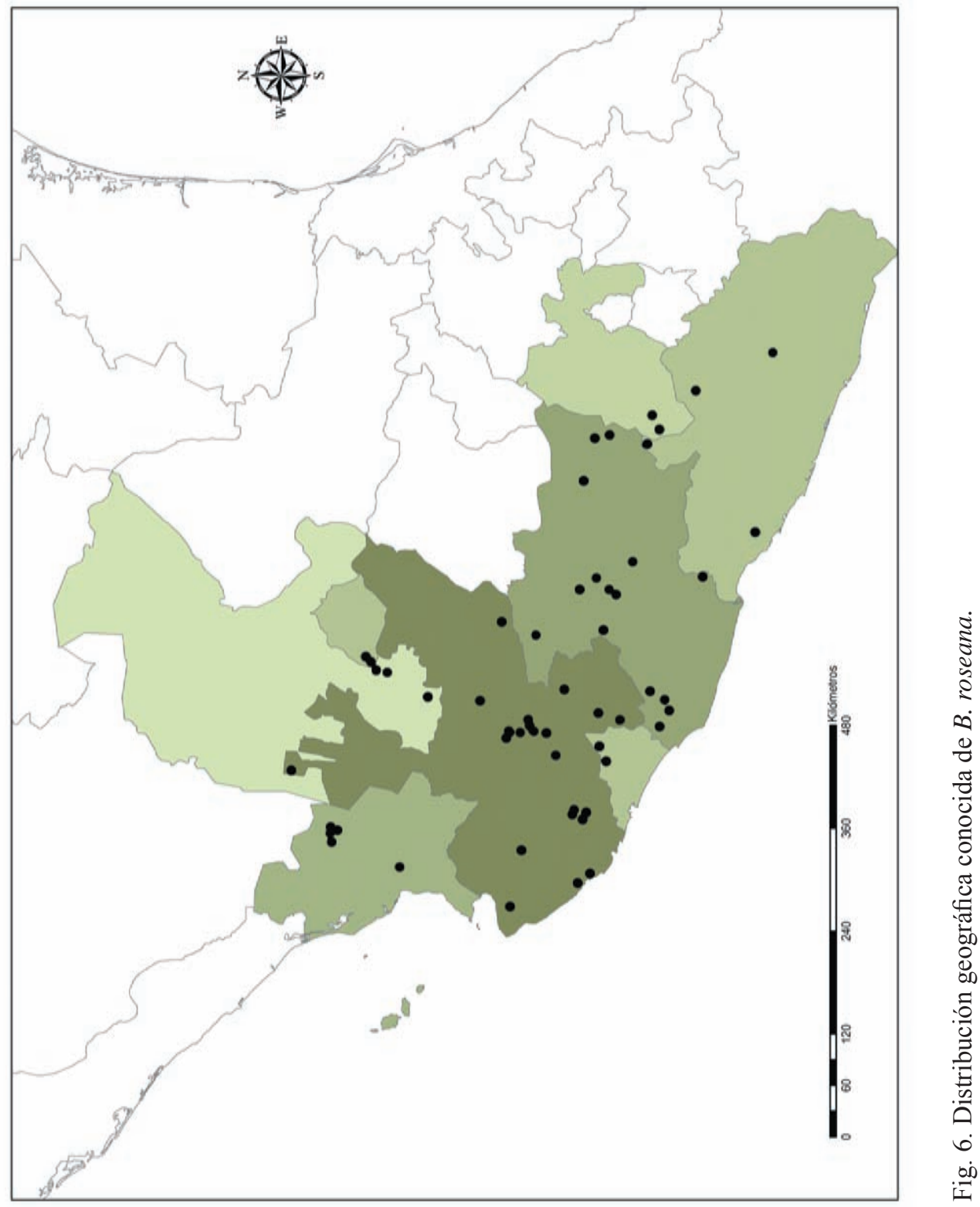


(MEXU), 3407 (MEXU); vereda de la Mesa del Nayar al Cangrejo, que cruza por la barranca, 22¹5' N, 10440' W, R. Ramírez et al. 562 (MEXU); a 17 km de Jesús María, sobre la carr. a La Mesa del Nayar, $22^{\circ} 15^{\prime}$ N, $104^{\circ} 37^{\prime}$ W, municipio de Nayar, R. Ramírez y G. Flores 1073 (ENCB, MEXU).

Jalisco: isla grande en la Laguna de Sayula, $3 \mathrm{~km}$ de Atoyac, municipio de Atoyac, M. Cházaro B. y R. Acevedo R. 7227a (IEB); rancho Arroyos de Agua, 15 km al NW de Huejuquilla, municipio de Huejuquilla, A. Flores M. 2001 (IEB); rancho El Pedregal, a 1 km de la nueva penitenciaría, municipio de Ciudad Guzmán, Grupo de Ordenamiento Ecológico - Aspecto Vegetación 175 (IEB); Puerto Los Mazos, 15-16 km por la carr. Autlán de Navarro - C. Castillo, 1941'41" N, 104²3'54" W, municipio de Autlán, L. Guzmán H. y F. J. Santana M. 1446 (IEB); Barranca de Colimilla, municipio de Tonalá, R. Hernández-Galaviz 80 (IEB); El Romerillo, ladera sur del cerro Los Ávalos llegando por Piedra Gorda, cercanías de La Villita (antes Cacaluta), municipio de Zacoalco de Torres, J. A. Lomelí-S. 3247 (IEB, MEXU); brecha a San Marcos Evangelista, municipio de Jocotepec, J. A. Machuca N. 3261a (IEB), 3263 (IEB); brecha de San Marcos Evangelista a Los Pozos, municipio de Zacoalco, J. A. Machuca N. 3324 (IEB); ca. 5.5 miles north of Tecalitlán, R. McVaugh 14955 (ENCB, MICH); Cuesta de San Marcos, ca. 30 miles SW of Guadalajara, $R$. McVaugh 15036 (MICH); 5-8 miles about La Cuesta on road to Talpa, R. McVaugh 20323 (MICH); 6 miles southwest of Pihuamo, R. McVaugh 21975 (MICH); above the pass, 10 miles S of Autlán, R. McVaugh 21995 (MICH); ibid., R. L. Wilbur y C. $R$. Wilbur 1410 (ENCB, MICH); puente San Pedro, 5 miles SW of Tecalitlán, $R$. McVaugh y W. N. Koeltz 1306 (MICH); puente San Pedro, Tecalitlán, F. Miranda 9029 (MEXU); barranca de Colimilla, al N de San Gaspar, municipio de Tonalá, M. Negrete et al. 67 (IEB, MEXU); camino a la cascada, El Salto del Nogal, Sierra de Tapalpa, municipio de Tapalpa, $M$. Negrete et al. 95 (IEB); aprox. $10 \mathrm{~km}$ al S de Zacoalco, J. Rzedowski 15276 (ENCB); Puerto de Los Mazos, 15 km al S de Autlán, sobre la carretera a La Resolana, J. Rzedowski 37880 (IEB); 9 km al SW de Tecalitlán, sobre la carretera a Pihuamo, J. Rzedowski 37901 (IEB); alrededores de Los Pozos, municipio de Zacoalco, J. Rzedowski 54171 (IEB, MEXU); $12 \mathrm{~km}$ al S de Zacoalco, sobre la carretera a Sayula, municipio de Tachaluta, J. Rzedowski 54172 (IEB, MEXU); $4 \mathrm{~km}$ al NE de Casimiro Castillo, F. J. Santana Michel et al. 2800 (MEXU); 1 km al norte de Santa Rita, falda norte del C. Cueva de Tía Pancha, municipio de Ayotlán, M. A. Silva Farías 310 (IEB); El Veladero, 24 km al NE de Tamazula, carretera Jiquilpan - Colima, J. C. Soto Núñez 734 (ENCB, MEXU); márgenes de Verdía, municipio de Zacoalco, E. Villegas F. et al. 429 (MEXU); Puerto de los Mazos, municipio de Autlán, S. Zamudio y F. Guevara 4764 (IEB, MEXU).

Colima: $3.4 \mathrm{~km}$ al NW de Zacualpan, $2.4 \mathrm{~km}$ al N de Campo Cuatro, camino Campo Cuatro - El Terrero, 19²2'46" N, 10350'47" W, municipio de Comala, $R$. Cuevas G. y L. Guzmán H. 3950 (IEB, MEXU); rancho El Jabali, 22 km (airli- 
ne) NNW of Colima in the SW foothills of the Volcan de Colima, near 19²7.1' N, 10342.4' W, A. C. Sanders et al. 11080 (IEB); El Agostadero, rancho El Jabali, ca. $20 \mathrm{~km}$ (airline) NNW of Colima in the SW foothills of the Volcan de Colima, near 19²6' N, 10341.7' W, A. C. Sanders et al. 11101 (IEB); Volcan de Colima: rancho El Jabali, $22 \mathrm{~km}$ NNW of the city of Colima at the Jalisco state line, La Atarjea Canyon, $1.5 \mathrm{~km}$ SE of hacienda San Antonio, on the road to Comala, near $19^{\circ} 26^{\prime} 18^{\prime \prime} \mathrm{N}$, 10342'30" W, A. C. Sanders et al. 11480 (IEB); rancho El Jabali, 22 km (airline) NNW of Colima in the SW footlhills of the Volcan de Colima, near $19^{\circ} 26.6^{\prime} \mathrm{N}$, 10341.9" W, L. Vázquez V. y B. L. Phillips 642 (IEB).

Michoacán: $1 \mathrm{~km}$ antes de Paracho, municipio de Pajacuarán, I. García 1420 (ENCB); entre Pajacuarán y Paracho, I. García Ruiz 1882 (IEB); west-facing slopes of cerro de Carboneras above the río Cupatitzio, ca. $22 \mathrm{kms}$. of Uruapan, $R$. M. King y T. R. Soderstrom 4883 (MEXU); 15 miles S of Ario de Rosales, R. McVaugh 21939 (MICH); 10 miles S of Uruapan, R. McVaugh 21958 (MICH); cerca de Coalcomán, 1844'18.2" N, 103¹4'5.8" O, R. Medina Lemos et al. 4288 (MEXU); Coru Station, C. G. Pringle 8838 (MEXU, MICH); Puerto de Las Cruces, municipio de Coalcomán, J. Rzedowski 16666 (ENCB, MEXU); 30 km al N de Buenavista Tomatlán, sobre la carretera a Los Reyes, J. Rzedowski 37970 (IEB); Tzitzio, J. C. Soto Núñez 424 (MEXU); 26 km al SW de Coalcomán, camino a Villa Victoria, J. C. Soto y L. Cortés 2513 (MEXU); 17 km SE de Palos Marías, municipio de Coahuayana, J. C. Soto et al. 7209 (MEXU); cerro Coyota, $2 \mathrm{~km}$ al O de Coyota, $24 \mathrm{~km}$ al SO de Zitácuaro, entrando por la presa El Bosque, R. Torres C. y M. P. Ramírez de T. 13606 (IEB); cerro de la Silla, al E de La Garita, carr. a Jungapeo, municipio de Jungapeo, R. Torres C. y M. P. Ramírez de T. 13749 (IEB).

Estado de México: Las Pilitas, 9 km al SW de Nanchititla, camino a Peña Bonita, municipio de Tejupilco, F. González Medrano et al. 5831 (MEXU); Villa Neda, Temascaltepec, G. B. Hinton 7801 (MEXU); $10 \mathrm{~km}$ al S de Luvianos, A. Patiño S. 1545 (ENCB, IEB, MEXU).

Guerrero: $23 \mathrm{~km}$ by road N of coast road (Hwy 200) on road to Ciudad Altamirano, W. R. Anderson 12822 (MEXU); 8 km de la desviación a Chichihualco, dirección Chilpancingo - Chichihualco, 17³6'42.9" N, 99³3'57.3" O, R. Medina Lemos et al. 4043 (MEXU), $4044 b$ (MEXU); $4 \mathrm{~km}$ al E de Rancho Nuevo, municipio de Tololoapan, P. Tenorio L. et al. 1519 (ENCB, MEXU).

Como ya se indicó con anterioridad, $B$. roseana está estrechamente relacionada con $B$. attenuata y ambas a su vez son morfológicamente muy próximas a $B$. simaruba.

Este vínculo es tan cercano que, de aplicarse un criterio taxonómico más conservador, convendría ubicar a las tres como variedades o subespecies de una sola entidad. Por el momento, sin embargo, no resulta oportuno realizar los cambios correspondientes, ya que es más razonable esperar a que se sepa más acerca de los 
patrones de variación de la propia $B$. simaruba y se lleve a cabo una revisión monográfica de todos los componentes de este complejo.

El nuevo estudio comparativo de secuencias de ADN de estas plantas, que se encuentra ahora en proceso, probablemente podrá dar más luz para el mejor desciframiento de la taxonomía y filogenia del grupo.

El nombre de la especie se asigna a la memoria del destacado botánico norteamericano Joseph Nelson Rose (1862-1928), responsable del descubrimiento y de la descripción original de esta especie, así como de varias contribuciones trascendentes al conocimiento del género Bursera.

Como complemento de la presente contribución se intenta integrar una clave para la identificación de las 12 especies del complejo de $B$. simaruba, que se conocen de México y de Centroamérica.

El artefacto utiliza principalmente las características de hojas y de frutos maduros, que son en general los más instrumentales en la sistemática de Bursera y los más frecuentes de encontrar en los especímenes de herbario correspondientes a estas plantas.

Cabe advertir, sin embargo, que la clave deja sin posibilidades de determinación sencilla a una cuantiosa proporción de ejemplares individuales, y es preciso comentar que tal circunstancia obedece mayormente a que:

-existen todavía varias especies de este complejo que no se han dado a conocer;

-las flores, las inflorescencias y los frutos inmaduros carecen en la mayor parte de los casos de valor diagnóstico en este grupo de árboles;

-las especies en cuestión son por lo general bastante variables y no es raro que solapen en parte las amplitudes de variación de varias de ellas; de esta suerte con frecuencia es necesaria una serie de ejemplares de una localidad determinada para definir su correcta ubicación taxonómica;

-se han observado algunos casos (muy poco frecuentes) de variabilidad completamente inesperada de las especies; así, por ejemplo se registró un ejemplar de B. simaruba con los frutos pubescentes, un ejemplar de B. arborea con foliolos maduros de pubescencia similar a los de B. attenuata y otro completamente glabro desde la temprana juventud de las hojas, al igual que un espécimen con esta misma característica de $B$. cinerea.

El último punto mencionado reviste particular interés, pues podría ser indicativo de la existencia de probables híbridos y del fenómeno de introgresión genética. A este respecto cabe recordar que no es raro que dos o más especies del complejo 
de B. simaruba convivan o prosperen en lugares muy próximos entre sí. El caso más notorio de esta simpatría corresponde a la comarca costera de Huatulco, en el sur de Oaxaca, donde crecen en cercana vecindad B. arborea, B. instabilis, B. krusei, B. ovalifolia y B. simaruba.

Lo notable es, sin embargo, que al parecer no existe un abierto flujo de genes entre estos taxa y los individuos que claramente pueden identificarse como de ascendencia híbrida, son muy escasos o con más frecuencia faltan por completo.

En términos de distribución geográfica cabe observar que el grueso de las especies aquí consideradas restringen su área a la vertiente pacífica del continente; las excepciones a este patrón son $B$. simaruba (de muy amplia repartición), B. cinerea (planta del oriente de México) y $B$. ovalifolia (esencialmente presente a lo largo del litoral del Pacífico, pero prosperando también en la Depresión Central de Chiapas).

Clave para la identificación de las especies del complejo de B. simaruba conocidas de México y Centroamérica

1 Fruto pubescente.

2 Fruto de 4 a 6 mm de largo; foliolos (1)3(5); conocida de Guerrero y Oaxaca B. krusei Rzed.

2 Fruto de 7 a $10 \mathrm{~mm}$ de largo.

3 Foliolos (3)5; conocida de Guatemala y Honduras

B. permollis Standl. \& Steyermark

3 Foliolos (3)5 a 7(9); conocida de Sonora y Chihuahua a Morelos, Guerrero y Puebla

B. grandifolia (Schltdl.) Engl.

1 Fruto glabro.

4 Foliolos 5 o menos, ocasionalmente 7.

5 Foliolos en su mayoría 1 o 3, con menos frecuencia 5; inflorescencia de 1 a $3 \mathrm{~cm}$ de largo; braquiblastos y hojas arrosetadas frecuentemente presentes; planta restringida al ambiente litoral, conocida de Jalisco a Oaxaca .. B. instabilis McVaugh \& Rzed.

5 Foliolos 3 o 5(7); inflorescencia por lo general de más de $5 \mathrm{~cm}$ de largo; braquiblastos y hojas arrosetadas ausentes.

6 Frutos maduros de 9 a $15 \mathrm{~mm}$ de largo.

7 Hojas y ramillas densamente cinéreo-pubescentes en la juventud; frutos de 9 a $10 \mathrm{~mm}$ de largo; conocida del centro de Veracruz, norte de Oaxaca y de áreas adyacentes de Puebla

B. cinerea Engl. 
7 Hojas y ramillas glabras o pubescentes pero no cinéreas; frutos de 9 a $15 \mathrm{~mm}$ de largo.

8 Planta de la vertiente pacífica de México, de altitudes superiores a 1100 m; hojas pilosas o pubérulas en el envés, al menos en la juventud B. roseana nom. nov.

8 Planta de la vertiente atlántica, de altitudes inferiores a $1000 \mathrm{~m}$; hojas pubescentes o totalmente glabras

B. simaruba (L.) Sarg.

6 Frutos maduros de 6 a 8(9) mm de largo.

9 Ramillas y hojas densamente pubescentes en la juventud, por lo general también conservando los pelos en la madurez; conocida del centro de Veracruz, norte de Oaxaca y áreas adyacentes de Puebla B. cinerea Engl.

9 Ramillas glabras o casi glabras desde la juventud; plantas desconocidas de Veracruz, norte de Oaxaca y áreas adyacentes de Puebla.

10 Árbol epifítico; infrutescencias ampliamente piramidales, profusamente ramificadas; conocida solamente de Costa Rica B. standleyana L. O. Wms. \& Cuatrecasas

10 Árbol no epifítico; infrutescencias racemosas o brevemente paniculadas; conocida de Jalisco a Costa Rica

B. ovalifolia (Schltdl.) Engl.

4 Foliolos de las hojas principales (metáfilos) 7 a 13.

11 Plantas totalmente glabras desde la juventud; fruto de $9 \mathrm{~mm}$ o más de largo.

12 Fruto romo en el ápice; peciólulos filiformes; árbol hasta de 10(13) $\mathrm{m}$ de alto, conocido de la mitad oriental de la cuenca del Balsas (Morelos, Puebla, Guerrero y Oaxaca)

B. longipes (Rose) Standl.

12 Fruto puntiagudo en el ápice; peciólulos delgados pero no filiformes; árbol hasta de $35 \mathrm{~m}$ de alto, de amplia distribución en México y Centroamérica B. simaruba (L.) Sarg.

11 Plantas con al menos algo de pubescencia, a veces restringida a las bases de los peciolos o a las axilas de las nervaduras del envés de las hojas.

13 Foliolos glabros, salvo pequeños mechones compactos de pelos en las axilas de las nervaduras inferiores en el envés de las hojas; ramillas glabras; conocida de Sinaloa, Durango y Nayarit

B. attenuata (Rose) Riley 
13 Foliolos glabros o pubescentes, pero sin densos mechones de pelos en la base de las nervaduras en el envés de las hojas.

14 Frutos maduros de 6 a $8 \mathrm{~mm}$ de largo; infrutescencias de 2 a 5 $\mathrm{cm}$ de largo; ramillas, hojas e inflorescencias densamente cinéreo-pubescentes en la juventud; foliolos membranáceos en la madurez; corteza exfoliante del tronco roja oscura; conocida de Sinaloa y Durango a Oaxaca B. arborea (Rose) Riley

14 Frutos maduros de $9 \mathrm{~mm}$ o más de largo; infrutescencias por lo general de más de $5 \mathrm{~cm}$ de largo.

15 Planta de Centroamérica, Chiapas, Oaxaca y otras porciones de la vertiente atlántica de México ......... B. simaruba (L.) Sarg.

15 Plantas conocidas de Sonora al Estado de México y Guerrero, en la vertiente pacífica de México.

16 Hojas con los peciolos llevando densos mechones de pelos en su base, o bien totalmente glabras; foliolos de las hojas principales (5)7 a 13; planta de altitudes inferiores a $1000 \mathrm{~m}$ B. simaruba (L.) Sarg.

16 Hojas sin densos mechones de pelos en las bases de los peciolos, pilosas o pilósulas en las nervaduras en el envés, al menos en la juventud; foliolos de las hojas principales 5 o 7; planta de altitudes por lo general superiores a 1100 m; conocida de Nayarit, Zacatecas y Aguascalientes a Colima, Estado de México y Guerrero

B. roseana nom. nov.

\section{AGRADECIMIENTOS}

Los autores agradecen a la M. en C. Silvia H. Salas y al grupo de sus colaboradores de SERBO, A.C. (Sociedad para el Estudio de los Recursos Bióticos de Oaxaca, Asociación Civil) el especial esfuerzo que han dedicado al muestreo intensivo de los representantes de Bursera en el Istmo de Tehuantepec y en la región costera de Oaxaca. La amplia serie de sus ejemplares resultó ser de crucial importancia para el apropiado entendimiento de la individualidad y la variabilidad de B. ovalifolia. Se dan las gracias asimismo al Prof. Dr. Uwe Braun, director del Herbario de la Universidad Martin Luther de Halle, quien amablemente proporcionó una copia xerox del tipo de B. ovalifolia, así como a la Biól. Margarita de la Cerda, encargada del herbario de la Universidad Autónoma de Aguascalientes, por la información sobre los ejemplares conservados en la 
colección a su cargo. El Biól. Pedro Díaz Maeda tuvo la amabilidad de confeccionar los mapas de distribución.

\section{LITERATURA CITADA}

Andrés-Hernández, A. R. y D. Espinosa-Organista. 2002. Morfología de plántulas de Bursera Jacq. ex L. (Burseraceae) y sus implicaciones filogenéticas. Bol. Soc. Bot. Méx. 70: 5-12.

Becerra, J. X. 2003. Evolution of Mexican Bursera (Burseraceae) inferred from ITS, ETS and SS nuclear ribosomal DNA sequences. Molec. Phylog. Evol. 26: 300-309.

Becerra, J. X. y D. L. Venable. 1999. Nuclear ribosomal DNA phylogeny and its implications for evolutionary trends in Mexican Bursera (Burseraceae). Amer. Journ. Bot. 86: 1047-1057.

Bullock, A. A. 1936. Notes on the Mexican species of the genus Bursera. Bull. Misc. Inf. Kew 1936: 346-387.

Engler, A. 1883. Burseraceae. In: DC. Monogr. Phaner. 4: 1-169.

Engler, A. 1931. Burseraceae. In: Nat. Pflanzenfam. ed. 2. 19a: 405-456.

Espinosa, D., J. Llorente y J. J. Morrone. 2006. Historical biogeographical patterns of the species of Bursera (Burseraceae) and their taxonomic implications. Journ. Biogeogr. 33: 1945-1958.

Hemsley, W. B. 1886-1888. Biologia Centrali-Americana. Botany. vol. 4. R. H. Porter. Londres. 498 pp.

McVaugh, R. y J. Rzedowski. 1965. Synopsis of the genus Bursera L. in western Mexico, with notes on the material of Bursera collected by Sessé \& Mociño. Kew Bull. 18: 317-382.

Rose, J. N. 1906. Restoration of Terebinthus with its species. Contr. U.S. Natl. Herb. 10: $117-123$.

Rose, J. N. 1909. Additional species of Terebinthus. Contr. U.S. Natl. Herb. 12: 278-279.

Rose, J. N. 1911. Burseraceae. In: North Amer. Fl. 25: 241-261.

Schlechtendal, D. F. L. von. 1843. De plantis Mexicanis a C. Schiede M. Dr., Car. Ehrenbergio allisque collectis (nuntium adfert). Linnaea 17: 245-253.

Standley, P. C. 1923. Burseraceae. In: Trees and shrubs of Mexico. Contr. U.S. Natl. Herb. 23: 542-552. 